\title{
LAS DEVELACIONES GENEALÓGICAS EN ROBERTO BOLAÑO
}

\author{
The Genealogical Unveilings in Roberto Bolaño
}

\author{
Claire Mercier* \\ Bernardo Rocco**
}

Resumen

El ensayo analiza la articulación genealógica de la literatura, la locura y la violencia presente en La literatura nazi en América y 2666 de Roberto Bolaño (2010a y 2010b), con el objetivo de entender cómo estas problemáticas recurrentes en su obra son reelaboradas mediante la mimesis literaria. Asimismo, esta dimensión evidencia la actuación de una consciencia narrativa que utiliza la articulación genealógica como un modo crítico de aproximación a la realidad. En consecuencia, ambas novelas manifiestan una visión de mundo que constata, mediante la genealogía, los indicios que explicarían los procesos históricos del fenómeno global de la violencia.

Palabras clave: genealogía, literatura, locura, violencia, crítica.

Abstract

The essay analyzes the genealogical articulation of literature, madness and violence present in La literatura nazi en América and 2666 by Roberto Bolaño, with the aim to understand how these recurring problems in his work are reworked by literary mimesis. Also, this dimension shows the performance of a narrative consciousness that uses the genealogical articulation as a critical way of approaching reality. Consequently, both novels show a worldview that finds by genealogy signs that explain the historical processes of the global phenomenon of violence.

Key words: genealogy, literature, madness, violence, criticism.

\section{INTRODUCCIÓN}

En "La parte de Archimboldi" de la novela 2666 existe un pasaje acerca de la infancia de Hans Reiter que ayuda a ingresar en la problemática genealógica presente en la narrativa de Roberto Bolaño (2004). En el ejemplo siguiente el narrador omnisciente relata el peculiar gusto acuático de Reiter:

Cuando la tuerta lo bañaba en un barreño, el niño Hans Reiter siempre se deslizaba de sus manos jabonosas y bajaba hasta el fondo, con los ojos abiertos, y si las manos de su madre no lo hubieran vuelto a subir a la superficie él se habría quedado allí [...] Una vez el cojo, que a veces miraba cómo la tuerta lo bañaba, le dijo que no lo subiera, a ver qué hacía. Desde el fondo del barreño los ojos grises de Hans Reiter contemplaron el ojo celeste de su madre y luego se puso de lado y se dedicó a contemplar, muy quieto, los fragmentos de su cuerpo que se alejaban en todas direcciones, como naves sonda lanzadas a ciegas a través del universo. Cuando el aire se le acabó dejó de contemplar esas 
partículas mínimas que se perdían y comenzó a seguirlas. Se puso rojo y se dio cuenta que estaba atravesando una zona muy parecida al infierno. Pero no abrió la boca ni hizo el menor gesto de subir, aunque su cabeza solo estaba a diez centímetros de la superficie y de los mares de oxígeno (p. 797-798).

La habilidad tanto acuática como contemplativa que permite a Reiter situarse entremedio de dos espacios disímiles -acuático y aéreo-, lo acerca bastante a la noción que tiene Aldous Huxley (1964) acerca de la experiencia anfibia: "Vivir anfibiamente, mitad en hechos y mitad en palabras, mitad en la experiencia inmediata y mitad en nociones abstractas, nos permite la mayoría del tiempo crear de forma artificiosa lo peor de ambos mundos" (traducción nuestra, p. 4). En este sentido, la posibilidad de Reiter de experimentar dos realidades de manera intermedia o simultánea es lo que facilita un acercamiento a la dimensión genealógica de las novelas de Bolaño. Según Colin Koopman (2013), la genealogía concierne la articulación filosófica e histórica de problemas que están sumergidos bajo la superficie de la vida cotidiana y que a primera vista parecen impenetrables. No obstante, son problemas que, a pesar de encontrarse sumergidos, están también presentes en la superficie de la vida cotidiana en la medida en que condicionan las acciones o los pensamientos de la sociedad (p. 1). De esta manera, Koopman entiende la genealogía como una práctica crítica que problematiza históricamente el presente y que tiene como objetivo traer a la luz aquellos problemas cotidianos que permanecen sumergidos (p. 2). Algo similar plantea Walter Benjamin (1978) respecto de la importancia rupturista del movimiento surrealista europeo cuando afirma que: "[...] penetramos el misterio solo en la medida en que lo reconocemos en el mundo cotidiano, en virtud de una óptica dialéctica que percibe lo cotidiano como impenetrable, lo impenetrable como lo cotidiano" (trad. nuestra, p. 190). Esta cita apunta precisamente al modo genealógico de la narrativa bolañesca, en la medida en que el escritor chileno busca explicar la lógica de la realidad actual a partir del develamiento de los nexos profundos entre diferentes sucesos históricos. En síntesis, la perspectiva genealógica permite a Bolaño elaborar un doble registro literario que convoca un pasado aludiendo a un presente, mediante la consideración de tres fenómenos de carácter histórico: la literatura, la locura y la violencia.

Respecto de la genealogía literaria presente en La literatura nazi en América (Bolaño, 2010a), esta consiste en el despliegue de una tradición literaria ficticia mediante una antología ${ }^{1}$ de escritores irreales correspondientes a un universo literario irreal. Esta especularidad paródica de la historia de una tradición literaria hispanoamericana tiene como objetivo no solo la desacralización y subversión de un cierto orden al interior de una tradición literaria establecida, entendida como un campo de producción y distribución de los saberes institucionalizados, sino que, a su

\footnotetext{
${ }^{1}$ Similar a la intención narrativa de El libro de los seres imaginarios de Jorge Luis Borges (1998), obra que fue originalmente publicada bajo el título Manual de zoología fantástica (1957).
} 
vez, da cuenta críticamente de un campo histórico-ideológico específico: el nazismo. En relación con la literatura, Lee Quinby (1995) señala que la genealogía:

[...] pretende desmitificar las devociones que todavía persiguen a la literatura mediante la búsqueda de la forma en que "lo literario" es delimitado, y de cómo los textos son producidos y distribuidos. También, atendiendo a las alteraciones del campo al destacar los modos de resistencia dentro de la literatura como de la crítica literaria y la teoría. La investigación genealógica asimismo expone los medios por los cuales tanto la literatura sacralizada como la crítica literaria y la teoría literaria fortalecen un orden de poder y conocimiento que justifica su jerarquía, cometiendo violencia en nombre de la moral y la verdad, y desactivando las posibilidades del cambio social (trad. nuestra, p. xi-xii).

Bolaño, mediante la articulación genealógica de un imaginario ficticio literario de tipo nazi en América Latina, también está reconfigurando y proponiendo un nuevo espacio escritural que expone críticamente los claroscuros de la modernidad latinoamericana o, si se prefiere, el escritor muestra los espacios grises de una tradición literaria considerada por la intelligentsia académica como un territorio sagrado. Un ejemplo que se estudiará posteriormente corresponde al del poeta experimental chileno de descendencia alemana Willy Schürholz nacido en Colonia Renacer, trasunto ficcional de Colonia Dignidad. La particularidad artística de su poesía consiste en la elaboración de planos de los campos de concentración de la Alemania nazi yuxtapuestos al plano de la Colonia Renacer. Luego de lograr cierta notoriedad artística durante la dictadura termina publicando, hacia fines del régimen militar, un libro de cuentos infantiles bajo el seudónimo de Gaspar Hauser. Como dice el narrador: "El libro, pese a las críticas, es un éxito de ventas. El personaje principal de Schürholz, el niño sin nombre, se convierte en el nuevo Papelucho de la literatura infantil y juvenil chilena" (Bolaño, 2010a, p. 105). La elaboración de una genealogía literaria toca aquí -paralelamente- algunas corrientes literarias, así como también eventos históricos traumáticos. Por una parte, la narración realiza una suerte de linaje temporal entre los eventos ocurridos durante la Segunda Guerra Mundial y los inmigrantes alemanes que llegaron a Chile huyendo del fin de la guerra, los que terminan también colaborando en el aparato represivo implementado por la DINA. Por otra parte, se establece una relación entre el arte de vanguardia europeo adaptado por Schürholz, que emplea para sobreponer la realidad de los campos de concentración europeos y chilenos, y la tradición de la literatura chilena infantil simbolizada por la serie Papelucho (1947-1974) de Marcela Paz. Es decir, el desarrollo de una genealogía literaria que desciende a los abismos experimentales del horror para caer casi huérfana en las manos creadoras de una mente asesina.

En relación con la perspectiva genealógica de la locura, se puede advertir que su descripción está conectada íntimamente a la noción metafórica de una enfermedad contagiosa y, por esta razón, posible de ser transmitida de persona a persona. Esta capacidad infecciosa ayuda también a trazar una historia de la locura que es 
canalizada por la biografía de Amalfitano. De esta manera, por medio de la experiencia de Amalfitano se mostrarán las ramificaciones y consecuencias políticas, personales y literarias del contagio de la locura. Es en "La parte de Amalfitano" donde se desarrolla específicamente el devenir existencial del profesor chileno, quien, a causa del golpe de Estado de 1973, se ve forzado a exiliarse primero en Argentina, para luego terminar viviendo en Barcelona, España. No obstante, la decisión de su esposa Lola de ir tras los pasos de un poeta loco recluido en el manicomio de Mondragón fuerza a que Amalfitano tome la determinación de radicarse junto con su hija Rosa en Santa Teresa, México. El viaje a la ciudad desértica, desencadenado por el abandono y la locura de su esposa, genera los primeros indicios de locura en Amalfitano, mientras intenta ajustarse a las nuevas condiciones vida en el norte de México:

La noche anterior a la excursión Amalfitano oyó por primera vez la voz. Tal vez antes la había escuchado, en la calle o dormido, y creyó que era de una conversación ajena o que tenía una pesadilla. Pero esa noche la oyó y no le cupo ninguna duda de que se dirigía a él. Al principio creyó que se había vuelto loco. La voz dijo: hola, Óscar Amalfitano, por favor no te asustes, no pasa nada malo (Bolaño, 2010b, p. 258).

Esta voz volverá a repetirse haciendo eco asimismo de un ambiente que ha sido infectado por los asesinatos de mujeres que parecen, en su serialidad, diseminarse como una plaga sobre la ciudad de Santa Teresa. En consecuencia, la locura es uno de los tantos elementos infecciosos que se replican especularmente y que dan cuenta de las condiciones de existencia moderna. En otras palabras, la perspectiva genealógica no solo manifiesta la transmisión de la locura, sino que también encauza otras formas de transmisión de enfermedades vinculadas al mundo contemporáneo, así como el sida, el narcotráfico o el exilio.

El tercer tema abordado desde la perspectiva genealógica es el de la violencia. En 2666 Bolaño plantea, mediante la mimesis literaria, una crítica trans-histórica y transespacial de la violencia, del mismo modo en que Benjamin entiende la crítica de la violencia. En otras palabras, como una filosofía de su historia en la que solo la idea de su desarrollo: "[...] hace posible una aproximación crítica, decisiva y discriminatoria de los datos temporales, donde al menos una mirada dirigida a lo que está al alcance de la mano puede percibir el ascenso y descenso dialéctico de las formas de elaboración y preservación de la violencia" (Benjamin, 2002, p. 251). Esto último es precisamente lo que se atestigua en uno de los argumentos colaterales de "La parte de los crímenes" donde Lalo Cura relata su historia familiar. La narración se inicia cuando Lalo Cura, en un estado entre el sueño y la vigilia, se entrega al recuerdo de las voces que entretejen un árbol genealógico atestado de escenas de violación, degollamiento, enfermedad, hambre y asesinatos. De esta manera, Lalo Cura desarrolla una extensa descripción que abarca más de un siglo de la historia de México, atestiguando cómo la violencia va elaborándose y reproduciéndose, así como 
también preservándose mediante la transmisión de generación en generación de las fuerzas destructoras de la existencia, para luego desembocar en su nacimiento y transformarse en un autodidacta de la criminología a cargo de la investigación de los asesinatos en serie de mujeres en Santa Teresa. En definitiva, el personaje de Lalo Cura, como el narrador de "La parte de los crímenes", es un protagonista dotado de una singular perspectiva transhistórica, es decir, que logra abstraerse de la lógica de normalización de la violencia histórica con el fin de entender su funcionamiento y criticarlo por medio, en este caso, de una atención particular otorgada a las víctimas, por lo general femeninas. De este modo, la crítica y resistencia al carácter difuso, así como cotidiano de la violencia, se efectúa por medio de un rescate textual de sus víctimas.

\section{CONSTELACIONES TEXTUALES}

\subsection{LA IRRUPCIÓN DE UNA TRADICIÓN LITERARIA}

En La literatura nazi en América, Bolaño traza la genealogía imaginaria y paródica de una supuesta literatura de ideología nazi en Latinoamérica. El texto cuenta con trece capítulos, los que presentan en total treinta autores, así como un "Epílogo para monstruos" que reúne, respecto de la seriedad burlona de esta falsa antología, breves descripciones de los autores mencionados, de las editoriales, revistas $^{2}$ y otros modos de difusión de la literatura nazi, así como una bibliografía de sus obras más relevantes.

Respecto de la estricta definición que relaciona la genealogía con la idea de familia, la obra presenta, por ejemplo, autores de una misma familia, los Mendiluce de Buenos Aires: Edelmira Thompson de Mendiluce y sus dos hijos, Juan y Luz ${ }^{3}$. Sin embargo, más que el retrato de una historia familiar, el texto se enfoca en una cierta crítica de la tradición literaria. A modo de ilustración, Juan Mendiluce se sirve de la revista familiar Letras Criollas para difundir sus diatribas en contra de Julio Cortázar, Jorge Luis Borges y Ernesto Sábato, entre otros, por ser autores: “[...] cultores de la violencia, el ateísmo y las ideas foráneas" (Bolaño, 2010a, p. 27). Es decir, se presenta la paradoja de que un autor de afiliación falangista ataque el canon de la literatura argentina debido a la supuesta promoción de la violencia. Algo similar ocurre con su hermana, en el episodio de su viaje de novios con el poeta argentino Julio César Lacouture, quien aprovecha la instancia para estar en compañía de varias prostitutas, mientras Luz intenta calmar su enojo en compañía de un autor mexicano

\footnotetext{
${ }^{2}$ A modo de ilustración, una de las revistas más importantes en términos de difusión de la literatura nazi en Latinoamérica es la del Cuarto Reich Argentino. La línea editorial de esta revista porteña consiste en rebatir la legalidad de los juicios de Núremberg y advertir sobre: "[...] el peligro bolchevique, el único real que amenaza a Europa desde el fin de la Primera Guerra Mundial”' (Bolaño, 2010a, p. 227).

${ }^{3}$ De hecho, el capítulo gira en torno a la mención de una foto que muestra a la pequeña Luz en los brazos de Hitler.
} 
revolucionario y un poeta argentino socialista. Los tres personajes hablan de: " $[\ldots]$ Baudelaire, de Mallarmé, de Claudel y de la poesía soviética, de Paul Valéry y de Sor Juana Inés de la Cruz" (Bolaño, 2010a, p. 29). La mención de la autora mexicana desata la ira de Luz quien lanza una figura en bronce de Atenea -diosa de la guerra y de la sabiduría- sobre la cabeza de su marido. Aparte de la relación de su marido con prostitutas, lo que enfurece realmente a Luz es su cohabitación forzada con una tradición literaria que el texto califica de "soviética". De esta forma, lo que está en juego en La literatura nazi en América es la parodia de un canon que consagra falsamente una tradición literaria bajo el formato de la antología. Es así como Bolaño construye una genealogía secreta y obscura o, mejor dicho, un anticanon que pone en jaque un cierto orden que rige la tradición literaria latinoamericana.

Uno de los autores mencionados en La literatura nazi en América que permite develar con más precisión el funcionamiento de la genealogía literaria es Willy Schürholz. Como ya se mencionó, Schürholz es un poeta experimental y su obra mayor consiste en superponer planos de Colonia Renacer con los: "[...] planos de los campos de concentración de Terezin, Mauthausen, Auschwitz, Bergen-Belsen, Buchenwald y Dachau" (Bolaño, 2010a, p. 103), acompañando la instalación artística con algunos versos escritos a mano. Respecto de la opinión del público, esta se divide entre quienes consideran la instalación poética como una crítica hacia la dictadura de Pinochet y de quienes ven una propuesta que restaura los campos de muerte nazis en Chile. Es así como el texto opera una superposición entre la Shoah y el autoritarismo militar chileno: dos empresas mortíferas. También, lo anterior denota una crítica hacia el hermetismo de la poesía experimental, si se consideran las opiniones totalmente contradictorias de los espectadores ante el galimatías de Schürholz. De hecho, el poeta chileno terminará su vida literaria escribiendo cuentos infantiles en torno a un niño sin nombre que se compara con Papelucho. Este giro hacia la literatura infantil se relaciona con la descripción de Schürholz como una persona casi retrasada mentalmente, que aprendió a hablar correctamente a los diez años y que, en la época de la exposición de los planos, todavía no sabía escribir bien. En suma, se está en presencia de un poeta casi analfabeto, de ideología milenarista nacionalsocialista, que transita sin mayores complicaciones entre una visión poética sobre los campos de concentración nazis y la literatura infantil.

Según La literatura nazi en América, Willy Schürholz sería un discípulo de Carlos Ramírez Hoffman, por la característica espacial de sus respectivas obras: tierra y cielo. El infame Hoffman ${ }^{4}$ permite de nuevo a Bolaño elaborar una genealogía entre el nazismo y la dictadura chilena, como en el caso de la exposición fotográfica o de su conversión en un director de películas pornográficas relacionadas con el hard core criminal: pornografia de la masacre. ${ }^{5}$ De este modo, lo que se critica, mediante esta

\footnotetext{
${ }^{4}$ Personaje que retomará Bolaño (2011b) en Estrella distante (1996) bajo el nombre de Carlos Wieder.

${ }^{5}$ Habría que relacionar esta mención de las películas pornográficas con el cuento "Prefiguración de Lalo Cura" en Putas asesinas (Bolaño, 2001), en el que se describe la carrera de la madre de Lalo Cura en el
} 
genealogía, es una estrategia de ocultamiento del crimen por medio de su estetización, así como la hipócrita consagración de una cierta poesía vanguardista. Esta empresa de sacralización se encuentra también ridiculizada a partir de la mención de una revista francesa en la que Hoffman habría participado y que pertenece al movimiento denominado "escritura bárbara" (207). El máximo representante de este movimiento es un antiguo portero parisino que durante Mayo 68: "[...] se encerró en su pequeño cubículo de la portería [...] y se dedicó a masturbarse con libros de Victor Hugo y Balzac, a orinar sobre libros de Stendhal, a embadurnar de mierda páginas de Chateaubriand, a hacerse cortes en diversas partes del cuerpo y manchar de sangre bonitos ejemplares de Flaubert, Lamartine, Musset" (207). En otros términos, se vanagloria irónicamente el potencial vanguardista de la poesía de un militar asesino, mientras se degrada el canon francés, en el contexto de protestas nacionales de tinte revolucionario, por medio de actos que podrían emparentarse con la actitud que tenía el régimen nazi respecto de la cultura letrada: los autodafés.

En resumen, en La literatura nazi en América Bolaño rompe el orden discursivo del canon literario occidental, con el propósito de realizar una crítica hacia la institucionalización de la literatura llevada a cabo por las antologías, por medio del establecimiento de genealogías que, a partir de los ejemplos anteriores, dibujan relaciones claras entre el nazismo y la dictadura militar en Chile: la colaboración del arte con la barbarie. En este sentido, se puede afirmar que el canon literario propuesto por Bolaño está relacionado más bien con ciertas lecturas, interpretaciones e influencias literarias que, en su conjunto y de manera indirecta, constituirían un canon bolañesco. Más precisamente, el canon se configuraría en torno a la noción del "lector modelo" de Umberto Eco (1993), entendido como aquel lector que mediante la actualización de su enciclopedia (p. 75) es: "[...] capaz de cooperar en la actualización textual de la manera prevista por [el autor] y de moverse interpretativamente, igual que él se ha movido generativamente" (p. 80). Por ejemplo, tal dinámica de presunción e institución de la competencia de un lector modelo (p. 80-81), elaborada por el autor, permite comprender la modulación narrativa que Bolaño expone hacia el final de "La parte de Amalfitano", donde el profesor chileno recuerda la conversación con un farmacéutico de Barcelona, desarrollándose un diálogo que informa de la conformación de un canon occidental constituido por obras menores y mayores como La metamorfosis versus $E l$ proceso de Frank Kafka. No obstante, como Amalfitano dice lamentándose: "Ya ni los farmacéuticos ilustrados se atreven con las grandes obras, imperfectas, torrenciales, las que abren camino en lo desconocido" (Bolaño, 2010b, p. 289), como es el caso de la misma novela 2666: mise en abyme.

cine pornográfico. También, con la referencia a las películas snuff en "La parte de los crímenes" de 2666 (Bolaño, 2010b). 


\subsection{LA LOCURA Y SU CONTAGIO}

En 2666 se traza la genealogía de la locura y su contagio a partir del personaje de Amalfitano. En un primer momento, "La parte de Amalfitano" da a conocer la locura de Lola, la mujer del profesor chileno, mediante su obsesión por un poeta loco, el que se encuentra en el manicomio de Mondragón. De hecho, la descripción del manicomio español actualiza el locus foucaultiano de la cárcel destinada a vigilar y domesticar los seres desviados 6 . Por su parte, la obsesión de Lola por el poeta hace pensar a Amalfitano que: "La locura es contagiosa [...]" (Bolaño, 2010b, p. 228), sin que se dé cuenta que la locura de Lola ya lo ha contaminado. En este sentido, una de las primeras manifestaciones de la locura del profesor chileno corresponde a la realización de un ready-made, consistente en colgar el libro de Rafael Dieste, Testamento geométrico, en el tendero de la ropa. Es el comentario de su hija Rosa respecto de la instalación vanguardista que introduce el tema de la creciente locura de su padre: "Espero que no te estés volviendo loco, dijo Rosa" (p. 246). La segunda manifestación del contagio de la locura reside en los esquemas geométricos de Amalfitano, acompañados de nombres de autores clásicos ${ }^{7}$ (p. 247-249), que ni el propio profesor de literatura entiende por qué los dibuja. Finalmente, estos dos síntomas confluyen en la irrupción de una voz en su mente. En la primera aparición de la voz (258-259), el texto se centra en la confusión de Amalfitano quien llega a pensar que se está volviendo loco. En cambio, en la segunda aparición (p. 266-270), la voz ${ }^{8}$ pone el acento sobre el sentimiento de vergüenza que la conciencia escindida del profesor chileno deja entrever respecto de su homosexualidad ${ }^{9}$. De este modo, en "La parte de Amalfitano", se pone en escena el contagio de la locura, fenómeno que se debe sin embargo considerar en relación con una genealogía más amplia: el linaje entre la dictadura pinochetista y los feminicidios mexicanos. En "La parte de los críticos" es cuando se menciona por primera vez la dictadura chilena y el exilio de Amalfitano (p. 156-157). Lo anterior se establece respecto de otra locura de tipo histórica: los crímenes de mujeres en Santa Teresa. De hecho, los dos fenómenos están interconectados por medio de las pesadillas del profesor chileno:

Aquella noche la voz no volvió a manifestarse y Amalfitano durmió muy mal [...] A esa misma hora la policía de Santa Teresa encontró el cadáver de otra adolescente $[\ldots]$ y un viento fuerte, que venía del oeste, se fue a estrellar contra la falda de las montañas del este, levantando polvo y hojas de periódico y cartones tirados en la calle a su paso por Santa Teresa y moviendo la ropa que Rosa había colgado en el jardín trasero, como si el viento [...] se probara las camisas y pantalones de Amalfitano [...] y leyera algunas páginas del Testamento geométrico [...]" (p. 260).

\footnotetext{
${ }^{6}$ Véase Vigilar y castigar. Nacimiento de la prisión (Foucault, 1997).

${ }^{7}$ Estableciendo un nexo con el arte nazi vanguardista de La literatura nazi en América.

${ }^{8}$ La que se presenta a la vez como el fantasma de su abuelo y de su padre.

9 En Los sinsabores del verdadero policía, Bolaño (2011a) vuelve a la figura de Amalfitano, concentrándose justamente en su homosexualidad.
} 
Por medio del viento, metáfora del contagio, se establece una genealogía entre los crímenes y la locura de Amalfitano ${ }^{10}$. De alguna manera, este devenir meteorológico establece además topográficamente una simultaneidad entre los distintos eventos trágicos que van siendo hilados por la fuerza del viento que, en su fantasmagoría, adopta la facultad lectora de hilvanar genealógicamente una interpretación paradigmática de lo que está aconteciendo en Santa Teresa. En definitiva, la locura es el resultado de un fenómeno de contagio que permite operar de un modo policial respecto de las pistas que conducen a una genealogía entre la dictadura chilena y los feminicidios mexicanos: elegibilidad forense.

En el prefacio a la edición de 1961 de History of Madness, Michel Foucault (2009) señala algo bastante atingente a la dinámica entre locura y genealogía observada en 2666 cuando se refiere a la posibilidad de escribir una historia sobre los límites de la locura que dé cuenta de lo que una cultura rechaza:

Interrogar una cultura sobre sus experiencias-límites es cuestionarla en los confines de la historia [...] que es algo así como el mismo nacimiento de su historia. Allí, en una tensión que está constantemente a punto de resolverse, encontramos la continuidad temporal de un análisis dialéctico enfrentado a la revelación $[\ldots]$ de una estructura trágica. En el centro de esta experiencia-límite del mundo occidental está la explosión, por supuesto, de lo trágico mismo. Nietzsche ha demostrado que la estructura trágica de la cual se forma la historia del mundo occidental no es otra cosa que el rechazo, el olvido y el colapso silencioso de la tragedia. Alrededor de esa experiencia, que es central, ya que anuda lo trágico a la dialéctica de la historia en el mismo rechazo de la tragedia por la historia, muchas otras experiencias gravitan. Cada una, en la frontera de nuestra cultura, traza un límite que simultáneamente significa una división original (Foucault, 2009, p. xxix-xxx).

De esta manera, la novela 2666 devela las relaciones entre la experiencia límite de la locura y la estructura trágica que yace en los confines de los procesos históricos que rechazan el elemento trágico presente en la locura. En consecuencia, el modo con el que Bolaño explica los procesos históricos de la locura reside justamente en aquellos elementos espacio-temporales que, en su articulación paradigmática, van conformando las diversas divisiones o genealogías acerca de las condiciones de vida en México. En el caso del elemento espacial, este aspecto puede verificarse en la representación, a lo largo de la novela, de tres lugares donde históricamente ha residido y se ha reproducido la locura: el manicomio de Mondragón, el manicomio de Santa Teresa y el manicomio Mercier. Es precisamente en torno a estos espacios de confinamiento del loco donde se exploran las ramificaciones temporales de la experiencia de la locura en su encuentro con la experiencia del evento histórico

\footnotetext{
${ }^{10}$ En "La parte de los crímenes", se establecerá de nuevo una relación entre los crímenes y la locura por medio del profanador de iglesias.
} 
trágico. Por ejemplo, mediante la biografia del profesor chileno, no solamente se desarrolla la experiencia de la locura de él en Santa Teresa y de su esposa en el manicomio de Mondragón, así como del exilio de Amalfitano producto del golpe de Estado en Chile, sino también se refieren a los asesinatos de mujeres en Santa Teresa como consecuencia directa de la guerra global al narcotráfico. Lo mismo sucede con Archimboldi quien, luego de experimentar los avatares de la Segunda Guerra Mundial, visita por equivocación el manicomio Mercier, lugar que, a nivel metafórico, ejemplifica el lenguaje remanente de la locura y el tiempo remanente de una generación de escritores que vivieron las consecuencias trágicas de la guerra europea, y que, por el viaje de Archimboldi a Santa Teresa, terminan experimentando -transmigratoriamente- la violencia en la frontera de México con Estados Unidos.

\subsection{LA TRANSMISIÓN DE LA VIOLENCIA}

En "La parte de los crímenes" de 2666 Lalo Cura $^{11}$ se acuerda de las voces ${ }^{12}$ que le hablan de su genealogía familiar. ${ }^{13}$ Esta se construye sobre un mismo patrón que alude a un linaje de mujeres de nombre María Expósito que han sido sistemáticamente violadas a lo largo de la historia. El relato genealógico se inicia cuando Lalo Cura, después de haber terminado de leer sus libros de criminología, reflexiona metódicamente acerca de su lucha en contra de la violencia en Santa Teresa:

[...] escuchaba o recordaba voces que le hablaban de la primera de su familia, el árbol genealógico que se remontaba hasta 1865 , con una huérfana sin nombre, de quince años, violada por un soldado belga en una casa de adobes de una sola habitación en las afueras de Villaviciosa. Al día siguiente el soldado murió degollado y nueve meses más tarde nació una niña a la que llamaron María Expósito (Bolaño, 2010b, p. 693).

Es así como esta génesis traumática se repetirá a lo largo de más de un siglo de historia mexicana, construyendo la genealogía de Lalo Cura en torno a una transmisión involuntariamente genética de la violencia, como lo constata Alberto Bejarano (2010) en su artículo República de Expósitos, genealogías de la orfandad en 2666 de Roberto Bolaño: "Bolaño describe minuciosamente la cotidianidad de la construcción de la República mexicana, desde los tiempos de la lucha contra el invasor europeo (Maximiliano de Austria y Napoleón III), pasando por la Revolución mexicana, hasta la actualidad" (p. 37), Esta historia familiar cuenta excepcionalmente con el nacimiento de dos varones. El primero se llama Rafael y nace en 1917. Sin

\footnotetext{
${ }^{11}$ Personaje presente tanto en "Prefiguración de Lalo Cura" (Putas asesinas) como en Los sinsabores del verdadero policía. No obstante, en esta última, Pancho Monje -trasunto de Lalo Cura- es el guardaespaldas de la mujer de un empresario corrompido de Santa Teresa. Es decir, que en este caso y al contrario de 2666, Lalo Cura es un personaje que participa de la violencia.

${ }^{12}$ En relación con la voz que persigue a Amalfitano.

${ }^{13}$ Bolaño retomará este episodio de forma casi idéntica en Los sinsabores del verdadero policía. 
embargo, este personaje se inscribe también en una genealogía de la violencia, por ejemplo, cuando el relato da cuenta de su mirada de asesino (Bolaño, 2010b, p. 695) y de una conversación con su madre durante la cual esta le confiesa que es el vivo retrato de su padre: el Diablo (p. 695). Desde la misma perspectiva, Rafael emprende en su adultez un viaje - premonitorio- hacia Santa Teresa, con el fin de asesinar al hombre que violó a su hermana, para finalmente morir a manos de los amigos de este último. En otros términos, se presenta la historia de la nación mexicana como si fuese la manifestación de la conocida percepción que habitualmente caracteriza la violencia: un círculo vicioso. Lo anterior se encuentra además reforzado por las profesiones de los hombres violadores, todas vinculadas con la violencia: el soldado belga, un partisano de la revolución y un torero, entre otros. El segundo varón es Olegario Cura Expósito: Lalo Cura. En efecto, su madre opta por anteponer el apellido "Cura" al de "Expósito", ya que considera que este último es el símbolo de una familia huérfana y con el propósito de romper con el círculo de la violencia que ha marcado a su familia desde su origen. Respecto del nombre, su madre lo elige inspirada en el santo Olegario al que se encomiendan los cazadores. Finalmente, la madre de Lalo Cura decide inscribirlo no en la parroquia de Villaviciosa, sino en la de San Cipriano, intentando así alejarse de la espiral de violencia característica de la ciudad donde nació la dinastía de mujeres de nombre María Expósito. De hecho, Lalo Cura será uno de los pocos policías honestos de Santa Teresa que se involucrará en la caza de los criminales de mujeres ${ }^{14} \mathrm{y}$, más generalmente, en la batalla contra la violencia machista mexicana.

Esta transmisión genealógica de la violencia se tiene además que considerar como un tema que atraviesa toda la novela. En efecto, la historia de Lalo Cura se inscribe, por un lado, en "La parte de los crímenes" y la genealogía, de algún modo inconclusa, de los feminicidios en Santa Teresa, porque el texto no proporciona la identidad del culpable -0 culpables- de esta masacre. Por otro, "La parte de los crímenes" se encuentra intercalada entre "La parte de Fate" y "La parte de Archimboldi" que recíprocamente retoman este tema genealógico de la violencia, esta vez en un contexto histórico y geográfico más amplio. El personaje de Fate, un periodista negro estadounidense que cubre un combate de boxeo en México permite desarrollar una genealogía de la violencia en relación con la esclavitud ${ }^{15}$ y los crímenes de mujeres en Santa Teresa ${ }^{16}$. En otros términos, dos situaciones históricas en las que se procede a una matanza de orden racista. Por ejemplo, así se resume la naturaleza criminal del ser humano en un diálogo que tiene Fate con un hombre canoso en un restaurante cerca de Tucson:

\footnotetext{
${ }^{14}$ Es de hecho significativo que el episodio de la genealogía de Lalo Cura sea precedido por el listado de chistes machistas que se cuentan los policías de Santa Teresa.

${ }^{15}$ Principalmente por medio de las citas de un libro acerca de la esclavitud: La trata de los esclavos de Hugh Thomas (Bolaño, 2010b, p. 332, 334 y 340).

${ }^{16}$ Ciudad que es comparada con la urbe estadounidense de Detroit (Bolaño, 2010b, p. 362).
} 
Y es curioso, pues todos los arquetipos de la locura y la crueldad humana no han sido inventados por los hombres de esta época sino por nuestros antepasados. Los griegos inventaron, por decirlo de alguna manera, el mal, vieron el mal que todos llevamos dentro, pero los testimonios o las pruebas de ese mal ya no nos conmueven, nos parecen fútiles, ininteligibles. Lo mismo puede decirse de la locura. Fueron los griegos lo que abrieron ese abanico y sin embargo, ahora ese abanico ya no nos dice anda. Usted dirá: todo cambia. Por supuesto, todo cambia, pero los arquetipos del crimen no cambian, de la misma manera que nuestra naturaleza tampoco cambia (Bolaño, 2010b, p. 338).

En esta cita se elabora una genealogía de la violencia y la locura, pero lo más interesante reside en el fenómeno del ocultamiento, a causa de una banalización diaria, de la naturaleza criminal del ser humano. De esta manera, la cita anterior apunta precisamente al funcionamiento crítico de las genealogías, el que radica en un develamiento de relaciones olvidadas e inusitadas, con el fin de entender, en este contexto, el alcance y las ramificaciones de la violencia global. Respecto de Archimboldi, se está también en presencia de una genealogía de la violencia, esta vez en el contexto europeo de la Primera y Segunda Guerra Mundial ${ }^{17}$. Lo anterior se encuentra no obstante puesto en relación con Latinoamérica en el momento en el que Ingeborg se refiere a las pirámides teñidas por la sangre derramada de los sacrificios aztecas $^{18}$ (Bolaño, 2010b, p. 871-872). Esta alusión a la masacre como manifestación de una violencia intemporal se debe asimismo relacionar, en "La parte de Archimboldi", con el episodio de la matanza de judíos a manos de Sammer/Zeller (Bolaño, 2010b, p. 938-960) y la figura del chivo expiatorio que encarna el sobrino de Archimboldi, Haas, el presunto responsable de los crímenes de mujeres en Santa Teresa (Bolaño, 2010, p. 786).

En definitiva, los crímenes de mujeres en Santa Teresa constituyen la faceta de un evento histórico local correspondiente a un correlato histórico global de la violencia. Lo anterior se hace visible mediante el peculiar modo forense que Bolaño desarrolla en "La parte de los crímenes"19, transformando este modo discursivo en un dispositivo eficaz al momento de narrar los crímenes. En efecto, la distancia de la pericia forense y la pretendida descripción exhaustiva de cada caso permite establecer a contrapelo -mediante esa mirada que se quiere neutra y cercana a lo verdadero- un modo soterrado de la violencia. Más precisamente, Bolaño se apropia del discurso forense, lo estructura y transforma en un recurso performativo eficaz que permite

\footnotetext{
${ }^{17}$ Además, está la presencia de la problemática genealógica de Archimboldi desarrollada en "La parte de los críticos", la que se resolverá en la última parte de 2666.

${ }^{18}$ El texto retoma el tema de la violencia de la civilización azteca en "La parte de los crímenes" cuando Lalo Cura evoca el pozole, un plato tradicional que, según el policía, los aztecas cocinaban con trozos de carne humana (p. 592). Además, se tiene que mencionar, en relación con la temática del narcotráfico presente en 2666, que el neologismo "pozoleado" remite hoy al hecho de diluir el cuerpo de las víctimas de los narcos en ácido para borrar cualquier tipo de huellas: el cuerpo mismo del delito.

${ }^{19}$ Con algunas variantes de la crónica policial.
} 
hacer visible la naturalización de la muerte. Es decir, mediante el quiebre de un determinado sistema de representación literaria de la realidad, el narrador (re)presenta una particular imagen de la violencia ligada al poder y al ámbito histórico. De este modo, "La parte de los crímenes" da cuenta de cinco estadios históricos de producción y transmisión de la violencia. El primero corresponde a la etapa primitiva si se considera el basural El Chile en el que sujetos desechados del ámbito de la civilización conviven entre los restos arqueológicos de la producción capitalista de cadáveres. El segundo es la etapa feudal centrada en la dominación armada que los carteles de la droga ejercen sobre el territorio y la población para mantener su hegemonía respecto de los procesos de producción, venta y distribución de la droga. El tercer estadio se configura en torno a la problemática de la esclavitud presente en "La parte de Fate", considerada no como el estigma histórico de algunos países colaboradores del comercio esclavista, sino como un fenómeno global que se ramificó también a Latinoamérica. Lo anterior permite que se opere un nexo entre la trata de esclavos y la matanza de obreras de las maquiladoras respecto de una violencia histórica de tipo racista, así como un capitalismo depredativo. El cuarto estadio remite a la violencia de las dos guerras mundiales europeas que describe "La parte de Archimboldi". Finalmente, el quinto estadio lo constituye la violencia correspondiente al capitalismo salvaje que se hace visible por medio de los feminicidios mexicanos. En definitiva, los crímenes de mujeres manifiestan la cristalización de los diferentes estadios de la violencia histórica descritos anteriormente.

\section{CONCLUSIÓN}

El concepto de genealogía remite a la articulación crítica de nexos ocultos entre dos o más realidades problemáticas. Es precisamente lo que realiza Roberto Bolaño en su narrativa. En efecto, el escritor chileno opera superposiciones entre ámbitos geográficos, históricos y literarios disímiles, para justamente establecer, así como criticar, sus oscuras conexiones pasadas y actuales. Juan Carlos Galdo (2005), en su artículo Fronteras del mal / genealogía del horror: 2666 de Roberto Bolaño, plantea algo similar cuando se refiere a la intención, por parte de Bolaño, de trazar en 2666: "[...] una genealogía del mal, es decir, de historiarla, y, con más precisión, de seguir sus evoluciones (o circunvoluciones) a lo largo del siglo XX" (p. 27). Sin embargo, el crítico peruano no se aventura más allá de la descripción del motivo del mal o, mejor dicho, no se plantea la pregunta de la función narrativa de la genealogía. En primer lugar, el recurso a la genealogía en la narrativa de Bolaño es constante y no se circunscribe solamente a la transcendental problemática del mal. En este sentido, se puede afirmar que la genealogía es uno de los pilares arquitectónicos, paradigmáticos y alegóricos más importantes de la narrativa bolañesca. Ejemplo de lo anterior son las constantes reapariciones de los mismos personajes en sus diferentes novelas, como se evidenció a partir de la figura de Carlos Wieder, Amalfitano y Lalo Cura. En cierta 
medida, este aspecto resulta bastante enigmático debido a que algunos de sus personajes parecen estar sometidos a un proceso de constante reelaboración genealógica al interior del mismo universo bolañesco, como en el caso de Lalo Cura/Pancho Monje en Los sinsabores del verdadero policía. También, esta empresa genealógica se materializa por la repetición de ciertos temas, como se ha visto en el presente artículo. En efecto, casi todas las obras del escritor chileno cuentan con la mencionada tríada genealógica ${ }^{20}$, apuntando recíprocamente a la literatura y a la locura como manifestaciones de la violencia. En este sentido, la escritura genealógica de Bolaño tendría como propósito develar las múltiples formas de la violencia, pero con el fin de concluir que siempre es una sola. En otras palabras, Bolaño no solo describe un evento violento y sus ramificaciones espacio-temporales -como en el caso de "La parte de los crímenes"-, sino que, a su vez, manifiesta un momento que encarna paradigmáticamente -a la manera de la instantánea benjaminiana del movimiento surrealista- los patrones históricos de la violencia.

La configuración genealógica de los tres problemas esbozados lleva a una consideración final importante de la intención mimética de Bolaño por desarrollar esta compleja visión de mundo. Para Michel Foucault (1977), la genealogía no consiste en la búsqueda de un origen, sino al contrario, en la examinación de una descendencia que permite el descubrimiento, bajo el aspecto único de un rasgo o de un concepto, de una multitud de eventos en las que estos se formaron (p. 146). Es en este sentido específico que la genealogía, para Foucault, consiste en:

[...] identificar los accidentes, las desviaciones momentáneas o, por el contrario, los retrocesos totales, los errores, las falsas apreciaciones, y los cálculos erróneos que dieron origen a esas cosas que aún existen y que tienen valor para nosotros; es descubrir que la verdad o ser no descansa en las raíces de lo que sabemos y lo que somos, sino que en la exterioridad de los accidentes. (Foucault, 1977, p. 146)

En el caso de Bolaño, los relatos entretejen eventos trágicos de la historia de la humanidad revelando, en su encuentro con el cuerpo, el momento de su formación. Es la imagen de un cuerpo atravesado por episodios de guerra, narcotráfico o enfermedad lo que permite constatar la perspectiva genealógica y por tanto reflexiva o contemplativa en Bolaño. Como afirma Foucault al respecto:

El cuerpo es la superficie inscrita de eventos (trazada por la lengua y disuelta por las ideas), el locus de un Ser disociado (que adopta la ilusión de una unidad sustancial), y un volumen en perpetua desintegración. La genealogía, como análisis de la descendencia, está pues situada dentro de la articulación del cuerpo y la historia. Su tarea consiste en exponer un cuerpo totalmente inscrito por la historia y el proceso histórico de destrucción del cuerpo (Foucault, 1977, p. 148).

${ }^{20}$ Los detectives salvajes (1998), Amuleto (1999), Nocturnos de Chile (2000), entre otras. 
En consecuencia, a lo largo del estudio se ha intentado rastrear la arquitectura genealógica presente en la narrativa de Bolaño, con el propósito de comprender las motivaciones tanto estéticas como éticas tras esta perspectiva narrativa: la mimesis literaria de cómo el cuerpo es inscrito por la violencia y escrito por la iluminación genealógica.

Universidad de Talca*
Instituto de Estudios Humanísticos 'Juan Ignacio Molina'
Avenida Lircays./n., Talca (Chile)
cmercier@utalca.cl
Universidad Tecnológicade Chile**
Humanidadesy Educación
Av.San Miguel3552,Talca (Chile)
stereohead73@gmail.com

\section{OBRAS CITADAS}

Bejarano, Alberto. (2010). "República de Expósitos, genealogías de la orfandad en 2666 de Roberto Bolaño". Nómadas 33, 31-41.

Benjamin, Walter. (2002). "Critique of Violence". Selected Writings. Vol. 1. (19131926). Marcus Bullock and Michael Jennings (eds.). Cambridge: Harvard UP, 236-252.

— (1978). "Surrealism: The Last Snapshot of the European Intelligentsia." Illuminations: Essays and Reflections. Trans. Harry Zohn. New York: Schocken Books, 177-192.

Bolaño, Roberto. (2011a). Los sinsabores del verdadero policía. Barcelona, Anagrama.

— (2011b). Estrella distante. Barcelona, Anagrama.

— (2010a). La literatura nazi en América. Barcelona: Anagrama.

— (2010b). 2666. Barcelona: Anagrama.

- (2001). Putas asesinas. Barcelona: Anagrama.

Borges, Jorge Luis. (1998). El libro de los seres imaginarios. Madrid: Alianza.

Eco, Umberto. (1993). Lector in fabula: la cooperación interpretativa en el texto narrativo. Trad. Ricardo Pochtar. Barcelona: Lumen.

Foucault, Michel. (2009). History of Madness. Jean Khalfa (ed.). London: Routledge.

— (1997). Vigilar y castigar. Nacimiento de la prisión. Trad. Aurelio Garzón del Camino. México: Siglo Veintiuno.

— (1977). "Nietzsche, Genealogy, History." Language, Counter-Memory, Practice: Selected Essays and Interviews. D. F. Bouchard (ed.). Ithaca: Cornell UP, 139-164. 
Galdo, Juan Carlos. (2005). "Fronteras del mal / genealogía del horror: 2666 de Roberto Bolaño". Hipertexto 2, 23-34.

Huxley, Aldous. (1964). "The Education of an Amphibian". Tomorrow and Tomorrow and Tomorrow, and Other Essays. New York: The New American Library of World Literature, 1-39.

Koopman, Colin. (2013). Genealogy as Criticism: Foucault and the Problems of Modernity. Bloomington: Indiana UP.

Quinby, Lee (ed.). (1995). Genealogy and Literature. Minneapolis: Minnesota UP, xi-xxix. Thomas, Hugh. (1998). La trata de esclavos: historia del tráfico de seres humanos de 1440 a 1970. Trad. Victor Alba y C. Boune. Barcelona: Planeta. 